\title{
DEL EGOTISMO BAROJIANO
}

\author{
María Luisa Domínguez
}

Università di Catania

Andrés Hurtado y Luis Murguía son personajes cuya entidad y evolución novelística se enmarcan en una tipología característicamente barojiana: la del individuo que busca una razón vital a la existencia partiendo de una captación intelectualizada de la realidad, desde donde se plantean conflictos conducentes al hallazgo de una norma de vida que permita un devenir humano soportable.

De la totalidad de las figuras creadas por el escritor vasco es, con mucho, Andrés Hurtado quien más profundamente aborda la búsqueda de una verdad existencial, quien de manera más consciente asume la necesidad de encontrar una explicación racional del universo. Luis Murguía, por su parte, es el caso más patente de asunción de lo perentorio de la autolimitación como única forma válida de subsistencia. Son dos criaturas extremadas, que acaso no suponen sino la plasmación de dos fases de una sola realidad: la de la restricción, práctica profundamente ejercida por su creador. Es a través de caminos diversos, en esencia contrapuestos, como ambos personajes alcanzan su situación definitiva.

No intento ofrecer una descripción global del ámbito narrativo en el que se incluye el personaje; sólo pretendo analizar su evolución ideológica y su estado de conciencia, evolución que habrá de ser vista a la luz de la más radical de las oposiciones barojianas, la planteada entre reflexión y acción (entendidas como unidades en proceso, no como principios antitéticos). Esta oposición se resolverá en Hurtado en un predominio absoluto de la manía reflexiva sobre cualquier posibilidad de acción. Murguía aporta un nuevo elemento: su reflexión se convierte en estado único, no existe siquiera el intento de la acción, lo que concreta una situación de parca autosuficiencia que se resuelve en la práctica de hábitos autolimitativos.

Ésta es a grandes rasgos la situación evolutiva de los personajes con respecto a la oposición propuesta. Cabe, con todo, hacer una aclaración. Habrá de tenerse siempre en cuenta la presencia de dos unidades en la interpretación de los personajes que, como literarios, aparecen cerrados y captables en su totalidad: pro- 
ceso evolutivo y situación final, o solución vital en su caso, se presentan como elementos perfectamente discernibles; lo cual marca también diferencias y similitudes entre ellos.

\section{ANDRÉS HURTADO O LA REFLEXIÓN AUTOSUFICIENTE (El árbol de la ciencia, 1911).}

Andrés Hurtado desde el principio se presenta como individuo conflictivo. Ante un mundo que no comprende, ante unas relaciones familiares basadas en el desprecio y en la incomprensión — cuando no en un latente odio-, ante una situación general que le provoca dolor y que se le aparece como absurda, asume su ser solitario y busca el aislamiento:

[...] todo [...] le daba una impresión de dolor, de amargura en el espíritu. La vida en general, y sobre todo la suya, le parecía una cosa fea, turbia, dolorosa e indominable.

(Primera parte, 6).

Andrés Hurtado requiere un asidero para su crisis, algo que por definicion psíquica del propio personaje ha de buscar dentro de sí mismo; su ideal no puede ser nunca, apriorísticamente, el de la acción sino que habrá de encontrar un marco conceptual, racional, desde el que su espíritu pueda contemplar el mundo y explicárselo; sólo más tarde podrá recurrir a la acción. Lo que quiere hallar es «una orientación, una verdad espiritual y práctica al mismo tiempo» (Primera parte, 8).

Paralelamente a esta conciencia de crisis, va desarrollando una serie de mecanismos que marcarán su actitud vital. Su pesimismo dolorido y su naturaleza huraña se vierten en un escepticismo que poco a poco va a convertirse en actitud característica. Siempre analítico, pesimista, derivará hacia una posición de franca abstención práctica y de búsqueda de explicación cosmológica más allá de la cotidianeidad que se presenta como un engendro informe, absurdo, injusto y doloroso. La experiencia lo ratifica continuamnte. Sus prácticas como estudiante de medicina le muestran un universo plagado de dolor, ante el cual su sensación más inmediata es la del extrañamiento. Todos los hechos reales son reelaborados en términos de captación filosófica del mundo:

A los pocos días de frecuentar el hospital, Andrés se inclinaba a creer que el pesimismo de Schopenhauer era una verdad casi matemática. El mundo le parecía una mezcla de manicomio y de hospital; ser inteligente constituía una desgracia, y sólo la felicidad podía venir de la inconsciencia, de la locura.

(Primera parte, 10).

Sin embargo Hurtado no tiende hacia ese estado de inconsciencia desde el que olvidarse incluso de la propia capacidad pensante; en todo momento es consciente de la necesidad del análisis, de la imperiosidad de llevar la reflexión hasta límites extremos a fin de encontrar una esperanza de solución vital. Surge el concepto de inacción basado en la constatación de la imposibilidad de la justicia. Pe- 
ro - y éste es un gran acierto novelístico- la asunción de la inacción como solución vital, la resignación a la cotemplación eterna de un mundo injusto, no se plantea como un absoluto que habrá de regir la conducta del personaje sino que aparece sucesivamente como una transformación dialéctica según toma contacto con nuevos sucesos. Se puede hablar ya de dos vertientes en el protagonista de El árbol de la ciencia: una puramente especulativa, interior, propia de un individuo marcado por un afán analítico, que niega la pertinencia de la rebeldía como medio de consecución de situaciones más válidas éticamente; otra de exposición externa, donde se reconoce al menos la necesidad del gesto disconforme, donde se niega la resignación y el conformismo complaciente.

En todo caso, planteadas las cuestiones de interpretación racional del universo y de la vida del hombre en estado crítico, no evolucionará hacia el abandono a una creencia; quizá su propia afanosa manía interpretativa le hace concebir como metarreales, como inválidos en principio, incluso aquellos estados de conciencia a los que ha llegado mediante un laborioso esfuerzo de conceptualización. Es una inquietud espiritual la suya que se plasma hasta la saciedad y que se refiere las más de las veces a sí misma. Así se explican las casi continuas afirmaciones a favor y en contra de la posibilidad de un cambio social, dadas a veces poco menos que simultáneamente. En el fondo, todo viene a entenderse por su condición de hombre que especula con la posibilidad de una acción que nunca ejecuta porque nunca acaba de ver su validez operativa.

En palabras de Iturrioz, interlocutor de los devaneos mentales del personaje,

[...] ante la vida no hay más que dos soluciones prácticas para el hombre sereno: o la abstención y la contemplación indiferente de todo, o la acción limitándose a un círculo pequeño.

(Segunda Parte, 9).

Andrés responde escéptico:

Es lo que tiene de bueno la filosofía; le convence a uno de que lo mejor es no hacer nada.

(Id.).

Hurtado no puede aceptar estas proposiciones tan fácilmente, y su desazón, su sentimiento interior de fracaso, de actividad mental estéril se agranda. El mundo de los objetos reales deja de tener importancia específica y queda relegado al papel de elemento referencial de la reflexión del protagonista. Todo le parecía irreal «ante el problema planteado en su cerebro» (Id.).

Un hecho lo saca de su estado de apatía y de febrilidad reflexiva, la enfermedad de su hermano. En su intento de fortalecer la salud del niño va a poner en juego unas energías hasta entonces insospechadas en él. El traslado a un pueblo de la costa, el contacto con la naturaleza y la vida al aire libre parecen no sólo sentar bien al enfermo sino también a Andrés. Cuando nota que el niño progresa favorablemente, y coincidiendo con cierto aburrimiento de la vida provinciana, decide volver a Madrid y comenzar el ejercicio de su profesión.

Pero inevitablemente a un estado de tranquilidad sobreviene otro de crisis. Hurtado recibe la noticia de la muerte de su hermano. Se inicia una nueva etapa 
de reflexión continua que se explicita en sus conversaciones con Iturrioz. El derrumbamiento psíquico del personaje es absoluto:

Uno tiene la angustia, la desesperación de no saber qué hacer con la vida, de no tener un plan, de encontrarse perdido sin brújula, sin luz a donde dirigirse. ¿Qué se hace con la vida? ¿Qué dirección se le da? Si la vida fuera tan fuerte que les arrastrara a uno, el pensar sería una maravilla, algo como para el caminante detenerse y sentarse a la sombra de un árbol, algo como penetrar en un oasis de paz; pero la vida es estúpida, y creo que en todas partes, y el pensamiento se llena de terrores como compensación a la esterilidad emocional de la existencia.

(Cuarta parte, 1).

Una situación como ésta se resuelve en la aceptación de las mentiras vitales (la religión, el amor como solución de felicidad), cosa imposible para un individuo analítico, o en la abstención más completa. Sin embargo Andrés opta por otro camino, la acentuación de la reflexión en un intento de construcción de una hipótesis racional del universo y del hombre. Este acentuamiento reflexivo conduce al personaje a la confianza en la ciencia, en la razón pensante, única vía de eliminación de la mentira, único medio de desarrollo humano. En el bíblico árbol de la vida está el camino de la falsedad tranquilizadora, que oculta la verdad —el arbol de la ciencia - dolorosa, pero cierta y sola. La exclusiva salida para un individuo que ha desarrollado una compleja capacidad de análisis es la confianza en la ciencia, lo que ciertamente supone un amplio grado de abstención práctica. Supone también un predominio del mundo de la inteligencia sobre el de la voluntad: no se trata de desear, sino de comprender mínimamente e instalarse sucesivamente en lo comprendido.

Este relativo estado de confianza, sin embargo, es de inmediato alterado por la hipersensibilidad analítica del personaje, que no sólo le lleva a reflexionar sobre la realidad, sino también sobre su propia reflexión. La característica del hombre antisocial aparece ahora con más fuerza:

¿No era científicamente un poco absurdo el furor que le entraba muchas veces al ver las injusticias del pueblo? Por otro lado, ¿no estaba también determinado, no era fatal el que su cerebro tuviera una irritación que le hiciera protestar contra aquel estado de cosas violentamente?

(Quinta parte, 5).

Necesariamente, en este estado, la única forma de continuidad es la inacción; pero la inacción irrita a Hurtado; intenta refugiarse en la lectura, en el estudio, en los paseos por el campo:

Todos los sistemas que discurría para encauzar su vida dejaban precipitados insolubles, que demostraban el error inicial de sus sistemas.

(Quinta parte, 8).

Comienza a pensar en la posibilidad del matrimonio y en adoptar una vía de resignación epicúrea. Precisamente la solución final viene a través de la relación con Lulú. Es un matrimonio asumido con todos los presupuestos analíticos 
propios de un hombre reflexivo. Andrés encuentra en Lulú una mujer con la que conversar y con la que no tiene que fingir estados de equilibrio que no son los suyos; justamente así consigue alcanzar una existencia tranquila y mínimamente sosegada: se dedica a traducir artículos para una revista científica, pasea con Lulú..., ha logrado en fin un estado de sedación vital sin necesidad de renunciar a su esencia reflexiva.

Hurtado no quiere comprometer su situación con la llegada de un hijo. Lulú sin embargo queda embarazada y recomienzan los presentimientos en torno a su fracaso. De nuevo siente el peso de la contradicción del existir y de la imposibilidad de salvación. En un parto desdichado mueren madre y niño. A Andrés Hurtado todo se le ha derrumbado otra vez, ahora definitivamente. Sólo queda el suicidio.

Negando la posibilidad de hallar una solución vital mediante ei ejercicio de la reflexión y la contrucción de un elemental universo de relaciones, Baroja niega lo que Andrés Hurtado había conseguido.

\section{LUIS MURGUÍA O LA CONCIENCIA ASCÉTICA (La sensualidad pervertida, 1920).}

El rasgo más característico de la personalidad de Luis Murguía es su exacerbada sensibilidad. El personaje es consciente de ello y percibe como hostil el medio en el que ha de desarrollarse. Todo su camino personal va a quedar cifrado en una intencionada autolimitación a fin de construirse un estado de conciencia en el que pueda existir sin alterar dolorosamente su excitable condición. Murguía se presenta además como hombre francamente abúlico. De nuevo estamos ante unas nociones de tipo caractereológico definidoras de la posterior evolución del personaje. Parece que desde el principio opera el carácter ineludible de ciertas cosas que funcionan a modo de imposiciones sobre el personaje: se le impone su propio ser abúlico e hipersensible, se le impone su propia conciencia de fracaso. Para el protagonista de La sensualidad pervertida es el mundo mismo quien ocasiona el fracaso; éste no es producto de una conducta errónea por parte del hombre, sino que la sola presencia de la realidad externa lo implica. Dice en el comienzo de su autobiografía:

Soy un hombre inútil, un hombre sin fundamento, un hombre fracasado, sin proyectos y sin planes. La mayoría de mis amigos y conocidos creen que el fracaso mío es mi falta;; yo creo que no, que es la culpa de los demás, culpa de algo en donde yo no he intervenido, o, por lo menos, he intervenido muy poco. (Primera parte, 2).

Más adelante reaparecerá esta conciencia de fracaso impuesto, concebida como una suerte de fatalismo, como restricción intrínseca de la propia experiencia:

Una de las cosas que me sorprenden cuando pienso en mi destino es el aire de fatalismo que tiene. Todas las circunstancias de mi vida han tendido a hacerme un hombre aislado, disgregado, separado del rebaño.

(Primera parte, 6). 
El carácter introvertido de Murguía se manifiesta muy temprano. Ya en su época de estudiante no comparte las aficiones de la mayoría y se distingue por su falta de aspiraciones concretas. Al mismo tiempo, su especial sensibilidad le hace vivir muy enfebrecidamente la experiencia de la pubertad y el descubrimiento de su propia naturaleza sexual. El contacto directo o indirecto con la mujer o con la realidad del amor, al tiempo que le mortifica con obsesiones eróticas y con traumáticos complejos físicos, le hace descubrir que no es atractivo, ni gracioso, ni audaz. En lo que significa la experiencia del amor, como en casi todo lo que sucede con su vida, tiene la sensación de encontrarse al margen de los acontecimientos. Luis Murguía es el personaje barojiano en quien más se aborda -a pesar de las acostumbradas sutilezas vergonzosas del autor en este terreno- el planteamiento de una problemática emocional entendida como el choque entre la necesaria expansión erótica y los mecanismos de comunicación sexual imperantes, todo ello centrado en su individuo que presenta unas inusuales posibilidades de captación sensible.

Se configura un panorama escasamente susceptible de ser ocupado por unas relaciones eróticas normalizadas. Desde el momento en que esta limitación se evidencia el personaje va instintivamente recortando sus aspiraciones y su campo de acción. Surge así, en germen, el concepto de la necesaria autolimitación como única solución posible al problema existencial. Desde aquí se extenderá a todos los demás ámbitos la práctica de la superación del deseo y en último término de su eliminación. Suprimir el deseo para hacer lo propio con el dolor provocado por la insatisfacción es el único proyecto de existencia que comienza a entrever Murguía.

En un estado de plena conciencia de su condición abúlica, aflora cierto tímido ímpetu de dominación momentánea sobre las circunstancias, siempre constreñido a un marco temporal reducido y con el contrapeso de la vuelta cierta a la contemplación:

Sentía el temor de que los acontecimientos iban a escamotearme la vida como me iban escamoteando la juventud. Entonces ya pensaba que me contentaría con un año de vida intensa, de fiebre, y luego vivir al margen, es decir, un año de acontecimientos y el resto de la vida dedicado al comentario.

(Tercera parte, 1).

Sucesivamente se cerciora de ser un hombre poseedor de una rara voluntad, generalmente inapreciable; su relativo afán voluntarioso es pronto anegado en base a dos principios: la inadecuación frente a la realidad y sus propias cortapisas de autolimitación. Sólo le queda una vía ascética de desarrollo, un camino cercenado en su propio inicio.

Tras el análisis de su problemática existencial se impone como objetivos la independencia y el conocimiento. Para conseguir el primero intentará la menor complicidad con el sistema moral vigente, lo que deviene en la consecución de un alto grado de autonomía espiritual; para el segundo no tiene solución real dada su incapacidad para la voluntad, por lo que optará por la ficticia solución del conocimiento libresco. Sin ilusiones y discrepando de las costumbres sociales im- 
perantes, tiende a apartarse de la gente y a buscar una vida interior basada en la lectura y en la reflexión. Murguía es perfectamente consciente de su situación:

Naturalmente, yo no he ido al ascetismo por afición, sino por no ceder a las imposiciones del medio ambiente.

(Octava parte, 1).

Y tal situación reponde a un plan de vida trazado y recorrido consecuentemente con sus propias, internas y externas, mediaciones:

Vivir decorosamente, hacer el menor daño a los demás y tener la mayor satisfacción posible. No he pretendido la gloria, ni el dinero, ni la importancia social. Vivir y contemplar. Ese ha sido mi ideal.

(Tercera parte, 4).

Autolimitación de las aspiraciones, conciencia y aceptación de una existencia sin emociones: éste es el ideal de un hombre que siente la vida como algo superior a sus fuerzas. Una solución ascética que incluye la abstinencia sexual y un disciplinado control físico como protección individual y, al mismo tiempo, como sublimación de unas evidentes incapacidades tanto para la integración gratificante y satisfactoria en la sociedad como para la práctica del amor. Pero también un gesto sarcástico indeleble como adorno del resumen:

Nada de grandes proyectos ni de grandes esperanzas, nada de lazos apretados. He llegado a lo que en mi juventud me parecía la más triste necesidad de la vida: la necesidad de la limitación. Me contento con tener un pequeño éxito de conversación en una reunión de señoras, con llevar a casa una chuchería antigua que me parezca bonita y comprar algunos libros.

(Octava parte, 5).

Un recorrido desde la hipersensibilidad inicial hasta la casi imperturbabilidad última ribeteada de sarcasmo: la perversión de la sensualidad:

¿Qué quiere ustéd? Esto no es más que amor y entusiasmo disimulado por [las mujeres] y dolor por el fracaso.

(Epílogo).

\section{CAMINO DE PERFECCIÓN}

Si la solución adoptada por Munguía se asemeja a la de Hurtado en lo que se refiere al hallazgo de un estado contemplativo, no se puede decir lo mismo en cuanto al proceso seguido. En Murguía hay un planteamiento consciente, premeditado, de camino hacia la contemplación restrictiva; la manía reflexiva no posee en él, salvo en aisladas ocasiones observables sólo en su juventud, carácter de experiencia traumática; la resignación se percibe como elemento casi originario que conduce al personaje a la solución ascética final. Su última amargura irónica prueba de que la suya es una de las más autoconformes existencias plasmadas por Baroja - aporta un nuevo efecto de diferenciación. 
Hurtado, por el contrario, pretende integrar la reflexión en su práctica vital, con lo que ello conlleva de análisis exhaustivo y perenne de lo circundante. Para exponer acabadamente hasta qué punto alcanza el ímpetu reflexivo del personaje, conviene establecer una comparación con la primera figura que Baroja construye de un individuo problemático que trata de hallar la razón de su ser en el mundo, con Fernando Ossorio, protagonista de Camino de perfección (1902). Ossorio tiene el propósito de anular la presencia del elemento reflexivo en su diaria existencia. Quizá donde más radicalmente se manifieste la discrepancia con Hurtado sea en el planteamiento de la solución vital. Para Fernando Ossorio, la vía matrimonial aparece como un engaño, como una negación de sí mismo, como refugio en fin donde ocultar su captación conflictiva del mundo, lo que trae consigo incomunicación real entre marido y mujer, ocultamiento de unos estados reflexivos que pretende desaparezcan:

Dolores se cogía del brazo de Fernando y cerraba los ojos:

- Tú me llevas — solía decir.

- Pero me guías tú - replicaba él.

- ¿Cómo te voy a guiar yo si tengo los ojos cerrados?

- Ahí verás...

(Capítulo LVII).

De manera opuesta, Andrés Hurtado percibe la posibilidad de una relación matrimonial que integre la necesidad reflexiva plenamente asumida. Lulú no es obstáculo para su afán analítico sino receptor de su discurso autoexplicativo. El protagonista de El árbol de la ciencia no precisa entablar un proceso de alienación consigo mismo, no se propone el desarrollo de una personalidad superpuesta a la suya real:

Hemos llegado a querernos de verdad, porque no teníamos interés en mentir. (Séptima parte, 2).

La diferencia no puede ser más radical en este aspecto. El «Ahí veras...» de Ossorio es, en resumen, todo un acto de resignación aniquiladora. La relación matrimonial de Hurtado es, por el contrario, integradora de su totalidad humana, no disgregadora. De ahí la radicalidad de una reflexión que le acompaña hasta el final; de ahí, también, el suicidio de Andrés cuando Baroja lo somete a la lógica demiúrgica de los accidentes: cuando muere Lulú, cuando desaparece la única posibilidad sustentadora de la experiencia definitiva del protagonista.

«La vida no es buena ni mala, es como la naturaleza: necesaria», dice el novelista en Juventud, egolatría (1917). Sus criaturas literarias, afanadas en un propio e individual camino de perfección, proponen por encima de todo el argumento de la necesidad de la limitación. Quizá Pío Baroja no pretendiera sobrepasar los límites del egotismo. 